\title{
O PAPEL DO GRUPO PET NO AMPARO MENTAL, ACADÊMICO E SOCIAL AO DISCENTE COMO ATENUADORES DA EVASÃO UNIVERSITÁRIA
}

Gabriel Jiro Horie - jiro@ufpr.br Universidade Federal do Paraná - UFPR Av. Cel. Francisco H. dos Santos, no 210 84531-970 - Curitiba - Paraná

Gabriel Besseler Pereira de Souza - gabesseler@ hotmail.com Universidade Federal do Paraná - UFPR Av. Cel. Francisco H. dos Santos, $n^{\circ} 210$ 84531-970 - Curitiba - Paraná

Lucas Faganello Silva - lucasfaganello@ufpr.br Universidade Federal do Paraná - UFPR Av. Cel. Francisco H. dos Santos, no 210 84531-970 - Curitiba - Paraná

Bruno Christopher Aira Soria - bruno.aira.soria@gmail.com Universidade Federal do Paraná - UFPR Av. Cel. Francisco H. dos Santos, no 210 84531-970 - Curitiba - Paraná

Resumo: A evasão acadêmica é um problema de diversos cursos de diferentes universidades. Um dos objetivos do Programa de Educação Tutorial (PET) do curso de Engenharia Elétrica da Universidade Federal do Paraná (UFPR) é promover atividades para atenuar esse problema. Este trabalho consiste na apresentação de atividades para recepcionar os calouros, monitorias e eventos de saúde mental. Para a recepção dos calouros, são feitas quatro apresentações para os alunos, além de um manual com informações fundamentais acerca do curso e da universidade. Sobre as monitorias, foram realizadas atividades presenciais e virtuais, estas realizadas frente a pandemia deste ano. Com relação a saúde mental, o PET Mind promoveu eventos como seminário, rodas de conversa, aulas de yoga e confraternizações. As atividades trouxeram boas experiências para os participantes e para os organizadores. Com resultados positivos, o PET acredita que essas atividades diminuem a taxa de evasão dentro do curso.

Palavras-chave: Recepção dos calouros. Monitorias. Apoio psicológico. Atividades virtuais.

\section{INTRODUÇÃO}


A evasão acadêmica é um problema presente em todas as instituições de ensino, sejam elas públicas ou privadas. No caso das IES (Instituições de Ensino Superior) públicas, o índice de evasão anual tem variado em torno de $12 \%$, oscilou entre $9 \%$ e $15 \%$ durante um período analisado de 5 anos. (FILHO, 2007).

Segundo Santana (1996), “a evasão é um dos maiores e mais preocupantes desafios do Sistema Educacional, pois é fator de desequilíbrio, desarmonia e desajustes dos objetivos educacionais pretendidos". Desde 1995, quando foi constituída a Comissão Especial de Estudos sobre Evasão, através de Portaria SESU/MEC, as pesquisas brasileiras sobre evasão se tornaram mais frequentes. Essa comissão tem o objetivo de desenvolver estudos sobre o desempenho das Instituições Federais de Ensino Superior. Desde então, foram realizados alguns estudos acerca desta temática em algumas Instituições de Ensino Superior, sem uma ação global para diminuir a evasão.

Nesse contexto, um dos objetivos do Programa de Educação Tutorial (PET) é contribuir para a elevação da qualidade da formação acadêmica dos alunos de graduação, conforme portaria 976/2010. O PET foi oficialmente instituído pela Lei 11.180/2005 e regulamentado pelas Portarias $\mathrm{n}^{\circ}$ 1.632/2006 e $\mathrm{n}^{\circ}$ 1.046/2007, ou seja, a partir desse momento, o PET ganhou respaldo legal para manter suas atividades, e garantiu direitos essenciais aos seus integrantes.

Para diminuir a evasão acadêmica, o grupo PET promove diversas atividades com o intuito de auxiliar nas questões acadêmicas, sociais e mentais dos discentes do curso de Engenharia Elétrica da UFPR (Universidade Federal do Paraná). Neste trabalho, será citado ações para recepcionar os calouros, suporte a graduação, projeto relacionado com questões de ensino, e PET Mind, que promove eventos com foco em saúde mental.

\section{METODOLOGIA}

No contexto de diminuir a evasão dos alunos do curso de Engenharia Elétrica da UFPR, o grupo PET desenvolveu três tipos de atividades: a recepção dos calouros, o suporte a graduação e o PET Mind.

\subsection{Recepção dos calouros}

Para os alunos recém-ingressos, o grupo desenvolve atividades para motivá-los, conhecê-los, guiá-los, sanar dúvidas e apresentar o grupo e a universidade.

O primeiro contato ocorre na semana do calouro, que é a primeira semana letiva na UFPR. Nessa semana, são feitas diversas apresentações dos grupos estudantis, de pesquisa e de extensão. Dentre essas apresentações, está a do grupo PET, o qual divulga o programa, os projetos da equipe e convidam para participarem dos eventos organizados pelo grupo. Durante a apresentação, ocorre a entrega do "Manual do Calouro" (figura 1). Este manual contém informações básicas como: Mapa da UFPR, mobilidade acadêmica, resumo dos grupos de extensão e "Dicas de Veterano", um espaço destinado para conselhos dos alunos mais antigos. Além disso, o grupo recolhe dados dos novos alunos para futuramente poder realizar outras atividades do grupo, como o "apadrinhamento de calouros".

Figura 1 - Manual do calouro. 


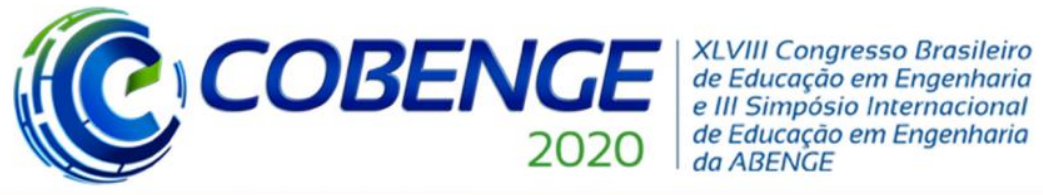

"Os desafios para formar hoje o engenheiro do amanhā"
$\mathrm{Ol} \mathrm{a} \mathrm{O3}$ de dezembro Evento On-line

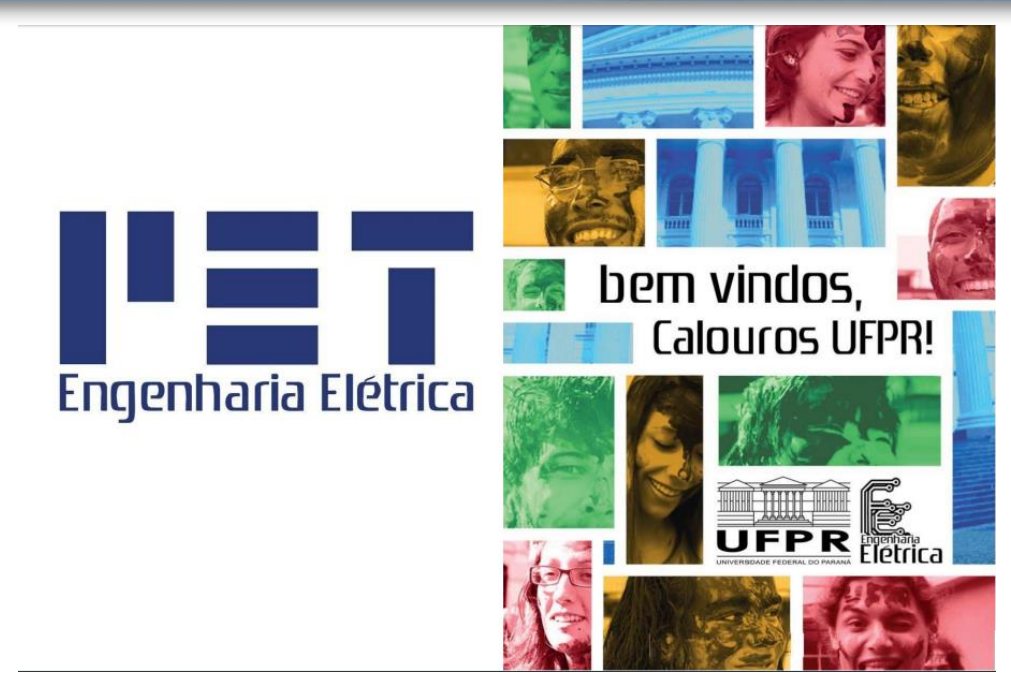

Fonte: OS AUTORES

Na mesma semana, é realizado o "Guia de Sobrevivência para Calouros", que ocorre da seguinte forma: alguns veteranos relatam as experiências que tiveram em seus anos de faculdade e contam como poderiam ter uma vida mais fácil. Esses conselhos incluem informações como o Intercâmbio, Atendimento Psicológico pela UFPR e o Centro de Línguas e Interculturalidade.

Em seguida, é feita uma oficina com a explicação de conceitos de eletrônica básica, além de serem mostrados alguns equipamentos de eletrônica, como por exemplo, o multímetro e a protoboard. Essa atividade traz experiências práticas e desperta o interesse dos alunos pelo curso, visto que, nos primeiros períodos, existe uma grande quantidade de matérias teóricas. No final da atividade, é feito o convite para a participação nas outras oficinas que o grupo oferta.

Em adição, o grupo organiza o evento "Coca no PET". Inicialmente, é feita uma dinâmica que consiste em explicar e analisar o conhecimento dos calouros sobre o PET, além de promover a interação e descontração entre eles. No final da dinâmica, os organizadores oferecem refrigerante aos participantes e os calouros podem conversar com os integrantes do PET e tirar dúvidas do curso e/ou do grupo.

No ano de 2020, essa dinâmica consistiu na divisão de 4 grupos e cada grupo recebeu um quebra cabeça, que, ao montado, revelava um pilar do PET. Esses pilares são: suporte à graduação, ensino, pesquisa e extensão. Ao final da montagem, o grupo discutiu entre si o que entendiam por aquele pilar e um representante foi até a frente da sala explicar.

Figura 2 - Coca no PET. 


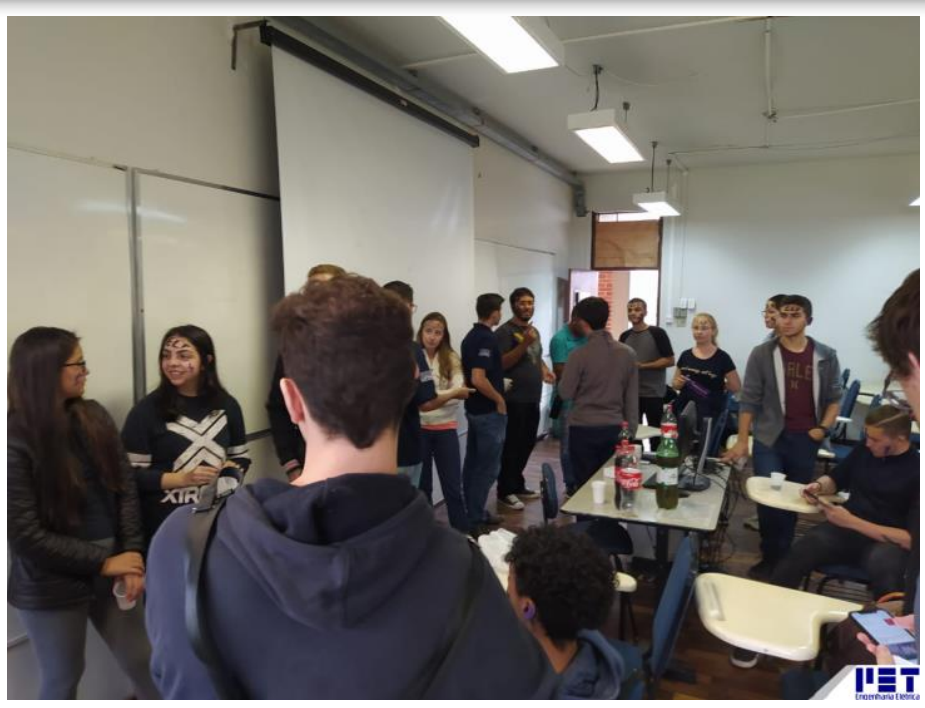

Fonte: OS AUTORES

\subsection{Suporte à Graduação}

Hodiernamente, o projeto "Suporte à graduação" consiste na elaboração de atividades direcionadas aos estudantes do curso que os auxiliem na sua vivência acadêmica, desde a realização de provas, resolução de exercícios e assimilação de conteúdo das diversas matérias presentes na grade curricular. Tais atividades acontecem com o intuito de estabelecer também o contato do grupo PET com os demais alunos e cumpre uma das bases do programa que é a indissociabilidade entre o ensino e a educação tutorial.

O projeto ampara toda a graduação, mas confere enfoque especial aos discentes do primeiro período, uma vez que, na maioria das vezes, esses têm o primeiro contato com diversas matérias bem como com a vida universitária. Historicamente no grupo PET, as atividades de amparo relacionadas à disciplina de Cálculo 1, obrigatória no primeiro semestre, tem sido o ponto alto do projeto. Nela, desde uma prova de nivelamento, monitorias direcionadas e acompanhamento contínuo dos alunos mostram resultados expressivos. São elaboradas também atividades com objetivo de ensino e reforço da matemática básica do ensino fundamental e médio, essenciais para o progresso do aluno em diversas disciplinas futuras, mas que carregam deficiências muito grandes. Ademais, ocorre também o suporte a outras disciplinas obrigatórias a esse período, tais como Física 1, Programação de Computadores e Geometria Analítica.

Com relação aos demais períodos, tal suporte se dá pelo apoio acadêmico nas disciplinas pelos PETianos que as cursaram e tiveram um bom aproveitamento. O objetivo é a troca de conhecimento de determinado assunto por meio de grupo de estudos, resolução de exercícios e dúvidas no conteúdo programático.

Todo ano, duas turmas ingressam no curso e o planejamento do grupo PET para auxílio nas matérias ocorrem geralmente em março e agosto.

No início do semestre, acontece uma prova de pré-cálculo para o nivelamento dos alunos que entram e análise de seu nível de conhecimento matemático, como visto na Figura 3. Com isso, é criado semestralmente um balanço das maiores dificuldades daquela turma, dividindo em áreas da matemática como trigonometria, funções, álgebra, entre outros. A partir dessa análise quantitativa, são criadas aulas específicas que variam semestralmente de acordo 
(C) COBENGE

"Os desafios para formar hoje o engenheiro do amanhã"
$\mathrm{Ol} \mathrm{a} \mathrm{O3}$ de dezembro Evento On-line

com as necessidades e focadas em sanar as dúvidas, resolver exercícios e transmitir um pouco da experiência do PETiano ministrante naquela disciplina.

Para isso, são criadas as monitorias de pré-cálculo, ministradas por PETianos e com frequência semanal. Em cada uma é reforçado um conteúdo, exercícios são resolvidos e listas são propostas.

Figura 3 - Monitoria Pré-cálculo (2020/1).

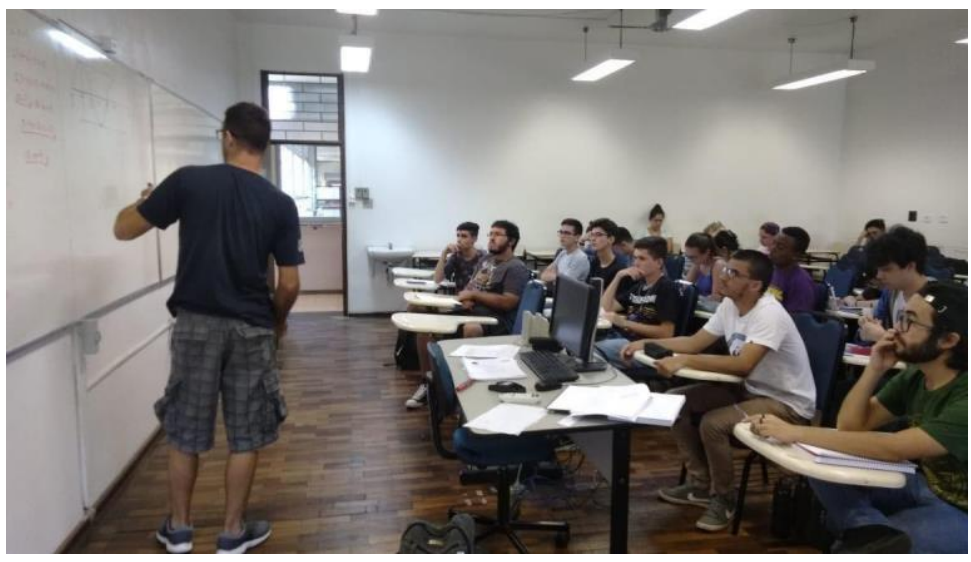

Fonte: OS AUTORES

No decorrer do semestre, ainda existe um acompanhamento e suporte aos estudantes do período nas disciplinas, especialmente direcionado àquelas que não são ofertadas pelos departamentos específicos. Essas monitorias são criadas conforme a necessidade da turma, tais como Cálculo 2, Física 2, Eletrônica Digital, Eletromagnetismo entre outras. Geralmente o conteúdo passado por um professor é reforçado e são resolvidas listas de exercícios.

Ademais, o projeto "Suporte a graduação" é desenvolvido junto ao "apadrinhamento de calouros", em que cada calouro tem um contato próximo com um PETiano. Eles se comunicam de forma que o calouro possa tirar dúvidas diversas, seja da universidade, conteúdo das disciplinas ou exercícios. Geralmente essa comunicação é feita por aplicativos como WhatsApp ou e-mail. Isso permite que o PET crie atividades que auxiliem o calouro na disciplina, seja enviando materiais, listas de exercícios ou até preparado monitorias específicas.

Em 2020, diante do cenário do Coronavírus, com as aulas suspensas e impossibilidade do contato físico, foi preciso reestruturar o planejamento e adaptar o projeto de forma online. O grupo reestruturou o planejamento e criou uma série de monitorias virtuais para os alunos, amparando-os nesse período delicado e dando continuidade aos objetivos do projeto.

Figura 4 - Monitoria Virtual (2020/1). 


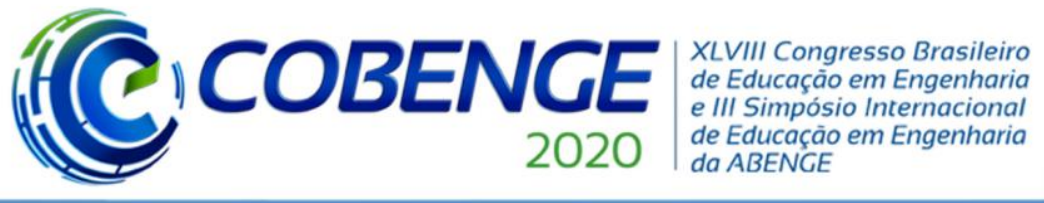

"Os desafios para formar hoje o engenheiro do amanhã"

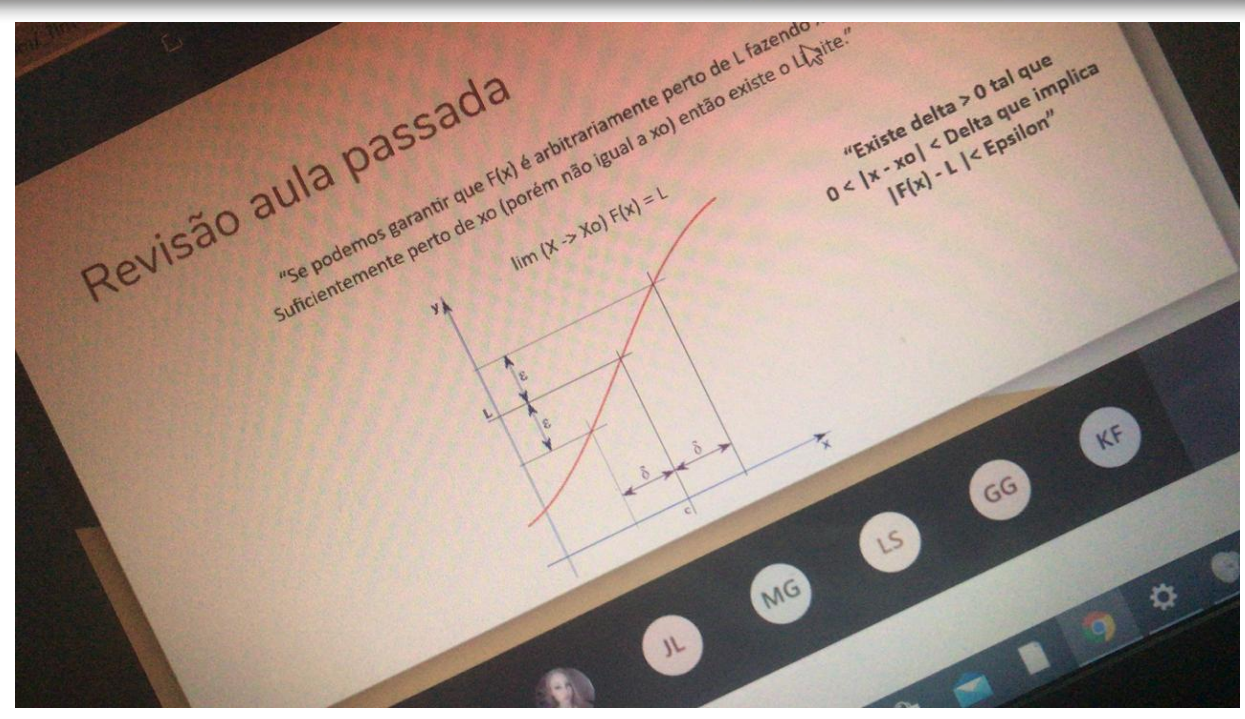

Fonte: OS AUTORES

Foram organizadas monitorias virtuais por meio do aplicativo Microsoft Teams, disponível pela UFPR e com possibilidade do aluno acompanhar a aula remotamente num smartphone, computador ou notebook.

\subsection{PET Mind}

Durante o ano de 2018, percebeu-se a necessidade de fazer atividades sobre saúde mental. Para isso, planejou-se realizar um seminário em língua estrangeira para discutir mais sobre o assunto. Posteriormente como projeto de trainee do processo seletivo, os candidatos criaram um evento sobre o tema. A atividade pensada foi uma roda de conversa com alguns professores do departamento de engenharia elétrica, pois há um certo distanciamento entre estes e os alunos. Para a realização dessa atividade, foi feito um formulário anônimo para que os alunos pudessem questionar os professores. Foram contatados alguns professores e foi divulgado o evento nas redes sociais e físicas do grupo.

No ano de 2019, planejou-se realizar mais 4 atividades para a comunidade acadêmica. 2 rodas de conversa com psicólogos, pois viu-se a necessidade de um profissional no desenvolvimento de tais atividades, e 2 aulas de Yoga. Para organizar as duas primeiras, foi contatada a PRAE (Pró-Reitoria de Assuntos Estudantis) para saber a disponibilidade dos psicólogos, reservando as salas e divulgando o evento posteriormente. Para as aulas de Yoga, entrou-se em contato com uma aluna da graduação que possui conhecimento no assunto para ministrar as aulas.

Além disso, percebeu-se também a necessidade dentro do próprio grupo. Foi planejado realizar confraternizações todos os semestres, além de atividades extras conforme necessidade. Para a execução dessas confraternizações, foram feitos formulários para decidir o melhor dia e horário. O grupo também era consultado em reunião ordinária para a decisão final do local e do momento da realização das atividades.

\section{CONSIDERAÇÕES FINAIS}

\subsection{Resultados e discussões}

$\mathrm{O}$ suporte à graduação tem um resultado expressivo e positivo no que cerne a ajuda aos alunos da graduação. Nota-se uma grande interação dos alunos com os PETianos durante 
aulas presenciais ou virtuais. A maioria deles participa da resolução de exercícios, tira dúvidas e pede auxílio nas listas sugeridas pelo professor.

No segundo semestre de 2019, foram realizadas 13 monitorias de Cálculo, inúmeros momentos particulares de troca de conhecimento entre os PETianos, os alunos e grupos de estudo.

Esse canal entre o PET e os discentes é fundamental para o desempenho do aluno durante as disciplinas da graduação. De forma quantitativa, também é possível notar uma melhora no desempenho.

No ano de 2020, o início do semestre aconteceu de forma como o planejamento. O grupo aplicou a prova pré-cálculo, corrigiu-as e obteve uma análise das maiores dificuldades desses alunos ingressantes. A partir disso, foram criadas as monitorias pré-cálculo. Com relação ao rumo que o projeto tomou frente a pandemia, utilizou-se o ambiente virtual. A resposta para essas monitorias foi positiva e houve um progresso na transmissão dos conteúdos os quais os alunos estavam com dificuldades. Além disso, foi percebida uma grande receptividade dos alunos e, até o final de abril, já foram transmitidos aproximadamente 21 horas de conteúdos por meio das monitorias online.

O projeto continua trazendo resultados e o objetivo futuro é ampliar cada vez mais a graduação e criar alternativas para que o aprendizado no ambiente acadêmico seja proveitoso e eficiente.

Quanto às atividades do PET Mind, foram realizadas, no total, 6 atividades para a comunidade acadêmica, contando com a presença de mais de 60 pessoas externas ao PET.

A primeira atividade realizada foi um seminário em inglês. Nesse ano, foi incluído também uma caixa de carinhos. Cada PETiano pode escrever uma mensagem carinhosa para outro membro, com o intuito de motivar e melhorar as atividades do grupo.

A figura 5 mostra a roda de conversa com professores. Nesta atividade participaram 3 professores e 35 alunos, incluindo alunos de outros cursos e universidades. Por meio de um formulário de feedback, os alunos disseram que queriam mais atividades como esta e que gostariam de profissionais da área. As principais questões trazidas pelos alunos do início do curso são referentes a tempo de estudo, matéria atrasada e dificuldade de concentração, enquanto os alunos no meio e fim do curso trouxeram questões de desmotivação. Também houve discussões sobre intercâmbio e distância da família.

Figura 5 - Roda de conversa com Professores (2018/2).

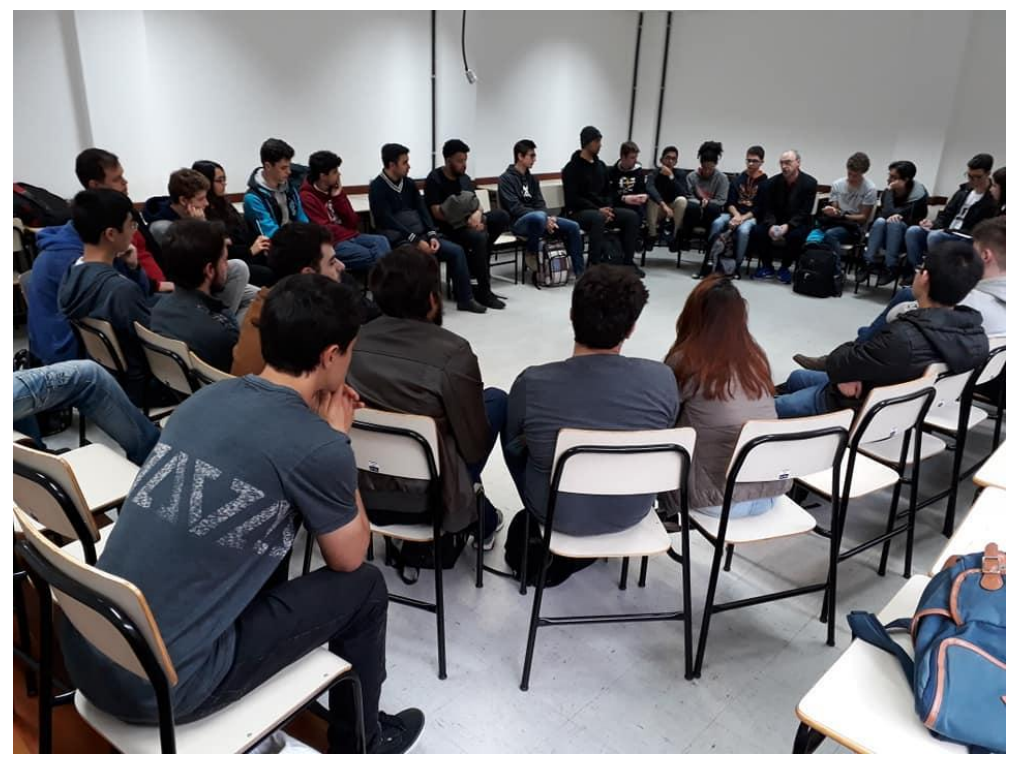




\section{Fonte: OS AUTORES}

Em resposta ao feedback, realizou-se 2 rodas de conversa com psicólogos da PRAE no primeiro semestre de 2019, contando com uma média de participação de 10 pessoas, como pode ser visto na figura 6 . Nessas rodas de conversa, os participantes fizeram desenhos e expuseram suas ideias em cartazes. Os cartazes foram colocados em murais dos prédios do Departamento de Engenharia Elétrica.

Figura 6 - Roda de conversa com Psicólogo (2019/1).

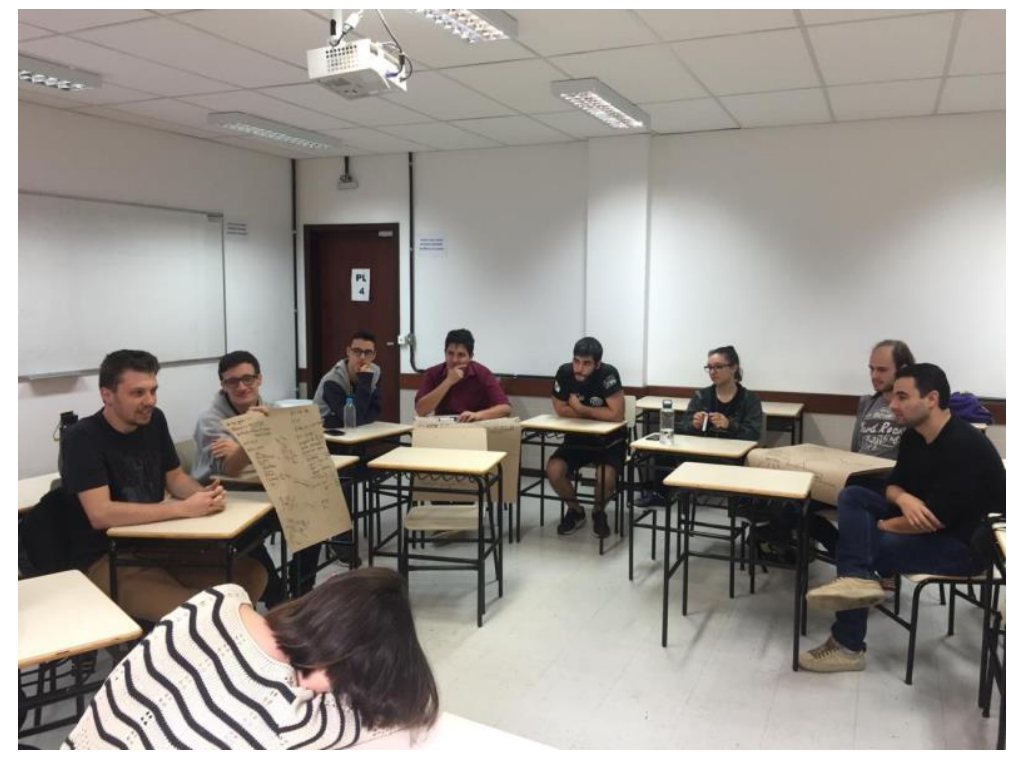

Fonte: OS AUTORES

No segundo semestre de 2019, viu-se a necessidade de inovar, realizando-se assim aulas de Yoga, como pode ser visto na figura 7. Foram realizadas 2 aulas, totalizando 10 participantes.

Figura 7 - Aula de Yoga (2019/2).

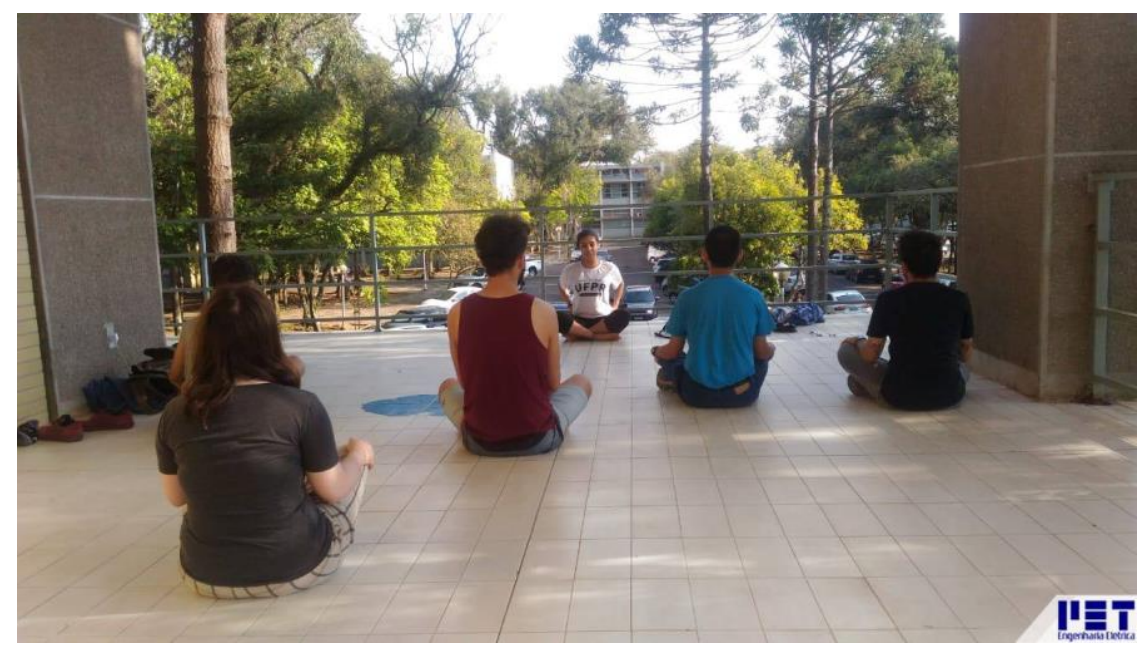

Fonte: OS AUTORES 
(C) COBENGE

"Os desafios para formar hoje o engenheiro do amanhã"

Para aumentar a integração do grupo e desestressar, o grupo realizou um desabafo do bem no segundo semestre de 2019, o qual consistiu em falar coisas boas que aconteceram nos últimos dias, além de escrever metas para o restante do semestre. Foram realizadas também confraternizações em todos os semestres, como pode ser vista na figura 8. As confraternizações variaram conforme o período do ano. Houve amigo secreto de Natal, boasvindas para novos PETianos e despedidas de membros. Nessas atividades, para que houvesse uma maior integração, houve jogos, desde clássicos do baralho até os mais modernos do videogame.

Figura 8 - Confraternização de fim de ano do PET Elétrica (2019/2).

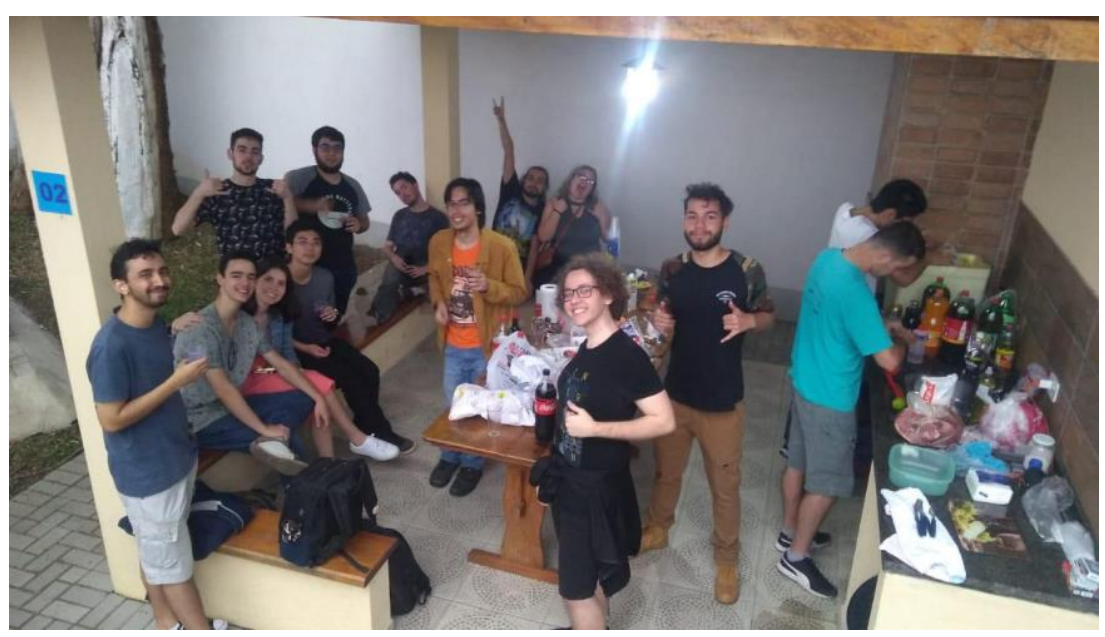

Fonte: OS AUTORES

\subsection{Conclusões}

Por meio dessas atividades realizadas, pode-se dizer que foram obtidos os resultados esperados. Por meio de ações direcionadas a recepção dos calouros, houve um amparo acadêmico e social para diminuir a evasão universitária. Além disso, com o suporte à graduação, houve um apoio nas disciplinas mais difíceis, não apenas para os discentes dos primeiros períodos, mas também para os discentes veteranos do curso. Por fim, os eventos do PET Mind auxiliaram alunos de todos os períodos, inclusive de outros cursos da universidade, na questão da saúde mental.

\section{REFERÊNCIAS}

BRASIL. Ministério da Educação. Gabinete do Ministro. Portaria no 976, de 27 de julho de 2010. Diretrizes do Programa de Educação Tutorial PET. Diário Oficial da União, Brasília, DF, 31 out. 2010 p. 40.

SANTANA, A. P.; PEROSSO, J. E. C.; MACEDO, K. L. O.; FARIAS, S. P. D de.(1996) Evasão escolar em escolas públicas municipais rurais localizadas em Montes Claros. Trabalho de Conclusão de Curso. Universidade Estadual de Montes Claros. Montes Claros: 1996

SILVA FILHO, Roberto Leal Lobo e et al. A evasão no ensino superior brasileiro. Cad. Pesqui., São Paulo, v. 37, n. 132, p. 641-659, Dec. 2007. Disponível em: $<\mathrm{http} / / / \mathrm{www}$. scielo.br/scielo.php?script=sci_arttext\&pid=S0100-

15742007000300007\&lng=en\&nrm=iso>. Acesso em: 01 mai. 2020. 


\title{
THE ROLE OF THE PET GROUP IN MENTAL, ACADEMIC AND SOCIAL SUPPORT TO STUDENTS AS ATTENUATORS OF UNIVERSITY DROPOUT
}

\begin{abstract}
Academic dropout is a problem in several courses from different universities. One of the objectives of the Tutorial Education Program (PET) of the Electrical Engineering course at the Federal University of Parana (UFPR) is to promote activities to mitigate this problem. This work consists of the presentation of activities to welcome new students, assistance in disciplines and mental health events. For the reception of new undergraduates, four presentations are made to students, in addition to a manual with fundamental information about the course and the university. About graduation support. face-to-face and virtual classes were carried out, which were carried out against this year's pandemic. With regard to mental health, PET Mind promoted events such as a seminar, conversation circles, yoga classes and social gatherings. The activities brought good experiences for the participants and the organizers. With positive results, PET believes that these activities reduce the dropout rate within the course.
\end{abstract}

Keywords: Freshmen reception. Teaching Assistant. Psychological support. Online activities. 